\title{
The Monterey Bay AquARIUM RESEARCH Institute
}

\section{By Richard T. Barber}

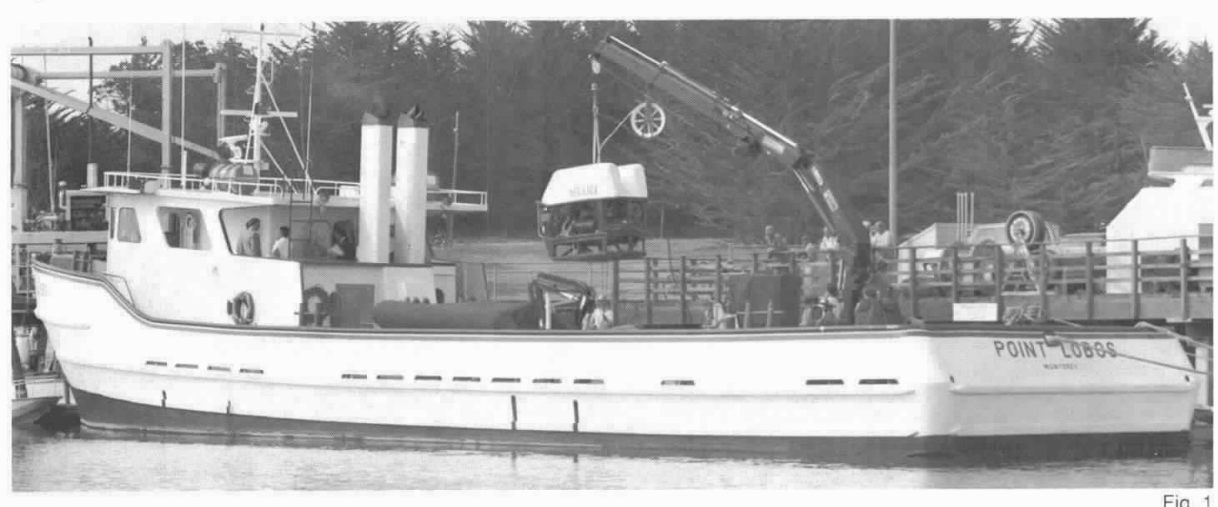

Fig. 1

\section{T}

1 HE Monterey Bay Aquarium Research Institute (MBARI) was founded in 1987 by David Packard to foster excellence in basic marine research and to exploit the unique research opportunities offered by Monterey Bay, Monterey Canyon, and the contiguous ocean waters of the California Current. The overall goal of the institute is to provide an improved understanding of the interrelated physical, chemical, biological and geological processes in the ocean, with a focus on the effects of temporal variability in climate and ocean circulation on food-chain processes, abundance of organisms, and geochemical fluxes.

Specific research objectives are:

- to describe the biota of Monterey Bay and the Monterey Canyon with the temporal and spatial resolution necessary to elucidate habitat groups, vertical migration and zonation, population structure, and other ecological processes;

- to determine the time-varying biological productivity and the transport of carbon and other biogenic elements through the open-ocean food web to the deep-sea biota and sediments; and

- to model the physical and chemical processes that determine the ecological and geochemical character of these waters using models that assimilate observations from an array of in situ sensors.

The institute is presently housed in a $1,500 \mathrm{~m}^{2}$ laboratory and office building in Pacific Grove, near Hopkins Marine Sta-

Richard T. Barber, Executive Director, MBARI, 160 Central Avenue, Pacific Grove, CA 93950. tion and the Monterey Bay Aquarium. A pier and operations facility is under construction in nearby Moss Landing. The pier will accommodate two $46 \mathrm{~m}$ and one $34 \mathrm{~m}$ ships simultaneously. An adjacent 2,100m² building will house support shops and environmental rooms.

The institute operates a $34 \mathrm{~m}$ vessel, the Point Lobos, built in 1980 (see Fig. 1). The vessel is outfitted with an articulated crane and a remotely operated vehicle (ROV). In addition to conventional navigation systems, the ship has several ultrashort-baseline positioning systems. Although Point Lobos is the size of a small expeditionary oceanographic research vessel, she will be operated principally as a "day boat" for repeated long time series observations and for work in the 1000 m-deep Monterey Canyon. The ROV has a $1850 \mathrm{~m}$ depth range. It is equipped with color and lowlight cameras, side scan sonar, a 7 function arm, a conductivity-temperature-depth (CTD) instrument, a fluorometer, an altimeter and a broad-band hydrophone. The initial tether for the ROV is about $700 \mathrm{~m}$ long, with 3 conductors and 10 fiber optic channels. Information from the ROV travels up to the ship via the tether; from the ship it is telemetered via a microwave link back to the lab where it will be accessible in "real time" to researchers from other institutions. A two-way (ship to lab) telemetry system will enable a research group to carry out a dive from the shore-based laboratory. The research group will be able to work in the context of an interactive computing sys- tem, utilizing visual identification of deepsea biota. By combining day boat operations and a telemetry system, we should be able to resolve the temporal variability of the coastal ocean and deep-sea. The institute also plans a moored array to provide continuous observations from Monterey Bay. In addition to various physical sensors for currents and temperature, combinations of moored sensors using fluorometry, particle counting, acoustics and sediment trapping are under consideration. The development of an in situ sensor for nutrients and/or inorganic carbon has a high priority. The institute is designed to increase the pace of scientific exploration, analysis and understanding of the coupled physical, chemical and biological processes of the deep ocean by implementing a focused program with the following elements:

- Merging of engineering and science to develop new technologies for in situ and remote sensing, for modeling and presenting data, and for the use of ROVs;

- Development of continuously recording in situ sensors for biological and chemical properties to resolve the variability of life processes with the same temporal resolution as that which is possible for physical properties such as wind, temperature, currents and sea level;

- Deployment of an in situ array in Monterey Bay and Monterey Canyon to test specific hypotheses on the role of physical and biological processes in driving geochemical processes along the ocean boundary; and

- Shifting the on-site human involvement in ocean and deep-sea research to remote, land based methodology to allow scientists and engineers access to enhanced real time computation and data analysis.

The institute is governed by a Board of Directors that includes several members of the Packard family and members of other research institutions; David Packard serves as Chairman. The institute has strong ties to the four Monterey Bay research institutions and to the Monterey Bay Aquarium. The institute is an outgrowth of the success of the aquarium; however, the mission of the aquarium is public education, while the mission of the institute is basic research.

David Packard has commented that we really don't know what is in the deep-sea or how the ocean system works together as a whole. He expects the Monterey Bay Aquarium Research Institute to "go deep and stay long" to provide answers that will improve our basic understanding of the ocean. 